\title{
The relation between dietary phytochemical index and metabolic syndrome and its components in a large sample of Iranian adults: A population-based study
}

Aazam ahmadi Vasmehjani

Shahid Sadoughi University of Medical Sciences and Health Services

Zahra Darabi

Shahid Sadoughi University of Medical Sciences and Health Services

\section{azadeh Nadjarzadeh}

Shahid Sadoughi University of Medical Sciences and Health Services

masoud Mirzaei

Shahid Sadoughi University of Medical Sciences and Health Services Yazd Research and Clinical Centre for Infertility

Mahdieh Hosseinzadeh ( $\sim$ hoseinzade.mahdie@gmail.com)

School of Public Health, Shahid Sadoughi University of Medical Sciences https://orcid.org/0000-0001-7482-2494

\section{Research}

Keywords: Dietary Phytochemical Index, metabolic syndrome, phytochemical-rich foods

Posted Date: June 24th, 2020

DOI: https://doi.org/10.21203/rs.3.rs-37118/v1

License: (c) (i) This work is licensed under a Creative Commons Attribution 4.0 International License. Read Full License 


\section{Abstract}

Background: Phytochemicals are natural non-nutritive bioactive compounds in plant foods. There is growing agreement that plant foods-based phytochemicals have a protective role against chronic diseases. The purpose of current study was to appraise Dietary Phytochemical Index (DPI) with the risk of metabolic syndrome (MetS) and its components.

Methods: This study was conducted on 2326 participants (1097 men and 1220 women), aged 20-70 years of the recruitment phase of Yazd Health Study (YaHS), a population-based cohort study on Iranian adults. Dietary intake was prepared using a validated and reliable food frequency questionnaire. DPI is calculated based on dietary energy derived from phytochemical-rich food sources (kcal)/ total daily energy intake (kcal). The odds ratio of MetS and its components were assessed across DPI quartiles by binary logistic regression models.

Results: After adjustment for all potential confounders, the risk of MetS (OR=0.63, 95\% $\mathrm{Cl}=0.41-0.96, \mathrm{P}=0.03)$ and elevated blood pressure (OR=0.62, $95 \% \mathrm{Cl}=0.40-0.96, \mathrm{P}=0.03$ ) in second category of DPI compared to the first significantly decreased. After full adjustment for confounders, women in the highest quartile of DPI compared with the lowest, had $59 \%$ lower risk of MetS $(\mathrm{OR}=0.41,95 \% \mathrm{Cl}=0.22-0.76, \mathrm{P}=0.005)$. In second quartiles of $\mathrm{DPI}$, the risk of MetS decreased by $62 \%(\mathrm{OR}=0.38,95 \% \mathrm{Cl}=0.16-0.90, \mathrm{P}=0.02)$ in participants with normal $\mathrm{BMI}$ and $29 \%$ in subjects with high $\mathrm{BMI}(\mathrm{OR}=0.71,95 \%$ $\mathrm{Cl}=0.52-0.99, \mathrm{P}=0.04)$, and also $57 \%$ in men $(\mathrm{OR}=0.43,95 \% \mathrm{Cl}=0.23-0.83, \mathrm{P}=0.01)$. Independent of variables including age, sex and total energy intake, subjects in second and fourth quartiles of DPI had $30 \%$ and $25 \%$ lower risk of abdominal obesity, respectively.

Conclusions: Greater adherence to phytochemical-rich diet could reduce odds of MetS and some components especially in women. Further studies with intervention approaches are required to discover causal relations and relevant underlying mechanisms.

\section{Introduction}

A set of cardiovascular risk factors, including abdominal obesity, hypertension, dyslipidemia, glucose intolerance, and insulin resistance indicates Metabolic Syndrome (MetS) [1, 2]. The global prevalence of MetS has been reported from lower than $10 \%$ to $85 \%$ [3]. Recent national data, showed that more than $30 \%$ of Iranian adults have MetS [4]. Various factors, including race, family history of diabetes, hypertension and heart disease, genetics, age, gender, lifestyle, diet and obesity are involved in the development of MetS [5, 6]. Identification of modifiable factors such as diet is essential to prevent the development of MetS [7].

Studies have shown increased intake of saturated fat and cholesterol [8], animal protein $[9,10]$ and high glycemic index foods [11] leading to risk of MetS. However higher intake of unsaturated fat [8], fruits and vegetables [12] are associated with a reduced risk of MetS.

For a long time, micronutrient deficiency was examining the role of nutrition in disease progression, but interaction of nutrients did not show full picture of link between food and chronic diseases, therefore dietary patterns was suggested [13, 14]. Recently, nutritionists have been focused on the combined effects of foods, thus the multivariate approach of food patterns was proposed [15]. Findings of studies have shown that the Mediterranean dietary pattern is high in vegetables and fruits, nuts, legumes, olive oil and low in saturated fat, moderate in fish and low to medium in dairy, low in red meat and poultry which the most health effects may be through phytochemicals compounds [16]. Phytochemicals are natural non-nutritive bioactive compounds including phenolic, isoperenoids and organosulfor compounds $[17,18]$. Due to the health-boosting effects of phytochemicals, dietary phytochemical index (DPI) suggested by McCarty as a percentage of calories derived from foods rich in phytochemicals [17]. DPI calculation seems to be a simple and inexpensive method of assessing the background of dietary quality as well as clinical applications [19].

Some studies have examined relationship between DPI and health benefits including oxidative stress, Inflammation, cancer and mental health [20-22]. Prior findings have shown an affluent diet in phytochemicals via antioxidant and anti-inflammatory properties has a protective role in the development of insulin resistance, abnormal glucose, lipid disturbances and abdominal obesity [23-26]. However, there are few studies that evaluated the relation between DPI and the occurrence of MetS. Therefore, the purpose of this study to investigate the association between DPI and the risk of developing MetS and its components in a large population of Iranian adults.

\section{Material And Method}

\section{Study design and participants}

This cross-sectional study was carried out on data obtained from two studies; Yazd Health Study (YaHS) and Taghzieh Mardom-e-YaZd (TAMYZ). YaHS is a population-based prospective cohort study of 10000 people aged 20-70 years randomly selected from 200 clusters of Yazd Greater Area including 50 participants per cluster ( 25 men and 25 women) and 5 persons in each ten years age groups. The profile of both studies was published elsewhere[27]. The recruitment phase of YaHS aimed to investigate the probability occurrence of chronic diseases and associated risk factors in Yazd Greater Area during 2014 - 2016. Yazd Nutrition Survey (YNS), locally known as TAMYZ in Persian, has evaluated dietary foods and supplements intakes of all participants of YaHS according to a validated food frequency questionnaire (FFQ). In this study participants with a history of diseases such as diabetes mellitus, cardiovascular diseases, stroke and cancer or persons whose total daily energy intake was less than 800 or higher than 6500 kcal were excluded. Finally, 2326 subjects were included in this analysis. Written informed consent was obtained from all participants. Ethical approval was obtained from the Ethics Committee of Shahid Sadoughi University of Medical Sciences, No. 17/1/73941. 


\section{Dietary assessment}

Dietary intakes were assessed through a validated (FFQ) consisting of 178 food items which was modified version of a previously validated 168 -item FFQ. Additional 10 questions relating to consumption of Yazd-specific food items were added to the original FFQ that were collected by trained interviewer $[27,28]$. Participants were asked about the frequency and usual amount consumption of food items that were converted to grams using guidelines of household scales [29].

\section{Phytochemical index calculation}

The DPI was calculated based on the method developed by McCarty in 2004; [[DPI = (daily energy derived from phytochemical-rich foods (kcal)/total daily energy intake $(\mathrm{kcal})) \times 100$ ]. Fruits, vegetables, legumes, whole grains, nuts, soy products, seeds and extra virgin olive oil were considered as phytochemical-rich foods. Coffee and tea, as free energy sources, were not contributed. Potatoes were not included as vegetables because of their low phytochemicals content. Natural fruit and vegetable juices as well as tomato sauces were included in the fruit and vegetable groups because of their high phytochemical content $[16,17,22]$.

\section{Anthropometric assessments}

Weight was measured using Omron BF-511 portable digital scales to the nearest $0.1 \mathrm{~kg}$ with minimum clothing and in standing position on scale. Height was measured using tape measure on a straight wall to the nearest $0.1 \mathrm{~cm}$, in a standing position without shoes by touching shoulders, buttocks and heels to the wall and head in Frankfurt position. Waist circumference (WC) was measured to the nearest $0.5 \mathrm{~cm}$ using non-stretch tape meter, while it is middle of the iliac crown and lowest rib in the standing position. Also, hip circumference was measured from the largest part of the buttocks with an accuracy $0.5 \mathrm{~cm}$. Body mass index (BMI) is calculated by dividing weight $(\mathrm{kg})$ to the square of height $\left(\mathrm{m}^{2}\right)$.

\section{Physical activity assessment}

International Physical Activity Questionnaire (IPAQ) was used to determine physical activity level. This Questionnaire based on Metabolic Equivalent (MET ) categorizes study population into three groups of sedentary, moderate and active [30].

\section{Diagnosis of metabolic syndrome}

MetS was diagnosed according to National Cholesterol Education Program Adult Treatment Panel III (NCEP ATP III). Participants who had at least three of following criteria were diagnosed as participant with MetS: Serum triglycerides $\geq 150 \mathrm{mg} / \mathrm{dL}$, Serum high-density lipoprotein cholesterol (HDL-C) $<40$ $\mathrm{mg} \mathrm{dL}$ for men and HDL-C $<50 \mathrm{mg} / \mathrm{dL}$ for women, Fasting blood glucose $\geq 100 \mathrm{mg} / \mathrm{dL}$, Blood pressure $\geq 130 / 85 \mathrm{mmHg}$ and Waist circumference $\geq 102$ $\mathrm{cm}$ for men and $>88 \mathrm{~cm}$ for women [31].

\section{Laboratory measurements:}

Laboratory measurements included of fasting blood glucose, HDL-C and triglycerides were measured according to a standard laboratory protocol using Pars Azmoon kits (Tehran, Iran) and calibrated Ciba Corning (Switzerland) auto-analysers.

\section{Assessment of other variables:}

Blood pressure was measured in a sitting position three times with a 5-min interval between each measurement. Other data including age, gender, marital status, education, job status and history of chronic diseases were collected through self-administered questionnaire.

\section{Statistical analysis}

DPI was categorized based on quartiles ranges. Characteristics of participants were compared throughout quartiles of DPI using one-way analysis for continuous variables and Chi-squared test for non-continuous. To estimate odds ratio and $95 \%$ confidence interval (OR ( $95 \% \mathrm{Cls}$ )) of MetS and its components in each quartile DPI and overall trend was used binary logistic regressions in crude and multivariable-adjusted models. These analyses were also conducted in two categories for BMI ( $\leq 24.9$ and $>24.9 \mathrm{~kg} / \mathrm{m}^{2}$ ) and sex (men and women) in crude and multivariable-adjusted models. Possible confounders which were considered in models were age (y), sex (men/women) and total energy intake (kcal/day) in the first model. Marital status (married/single/divorce/widowed), physical activity level (sedentary/moderate/active), smoking status (never/former/current), family history of chronic disease (yes/no), educational level (less than high school diploma/college/ university), job status (not employed/employed), house status (owner/not owner), family size (less than 4/more than five), house in square meters (less than 100 square meters/ between 100 to 200 square meters/more than 200 square meters), ethnicity (Native or non-native) in the second model. Along with other variables of the second model, BMI $\left(\mathrm{kg} / \mathrm{m}^{2}\right)$ was considered in the third model. Statistical analyses were performed by SPSS statistical software (version 23 ). P values less than 0.05 was statistically considered for significant level.

\section{Results}

General characteristics of the study participants across categories of DPI are shown in Table 1. Mean (SD) of DPI among the first, second, third and fourth quartiles categories was 12.5 (3.15), 19.4 (1.36), 24.53 (1.79) and 36.08 (9.2), respectively. Mean score of DPI in women and men was (23.2 and 
23.05), respectively. There were no significant differences in BMI, WC, marital status, education, smoking, job status and physical activity levels across quartiles of DPI but age of participants was significant throughout quartiles $(p=0.04)$. The prevalence of MetS and its components was not significantly different across quartiles of DPI except for abdominal obesity $(P=0.04)$.

\section{DPI and dietary intake:}

Mean dietary intakes of participants across quartiles of DPI are provided in Table 2. Participants

in the upper quartile of DPI have higher intakes of whole grain, vegetables, fruits, legumes, nuts, vitamins C, vitamin A, folic acid, pantothenic acid, iron and potassium to compare with those in the bottom quartile ( $p$ for trend<0.001). Participants in the highest DPI, have lower intake of energy, total fat, monounsaturated fatty acids (MUFA), saturated fatty acids (SFA), polyunsaturated fatty acids (PUFA), cholesterol, total fiber, vitamin E, zinc, calcium, magnesium ( $p$ for trend $<0.001)$. No significant difference was observed across quartiles of DPI for Docosahexaenoic acid $(\mathrm{DHA})(\mathrm{p}$ for trend $=0.68)$ and Eicosapentaenoic acid (EPA) ( $\mathrm{p}$ for trend $=0.74$ ). Also, mean consumption of coffee and tea was more in women, $423.37 \mathrm{ml} / \mathrm{day} \mathrm{vs} 421.13 \mathrm{ml} / \mathrm{day}$.

\section{DPI and MetS and its components:}

The odds ratio ( $95 \% \mathrm{Cls}$ ) of MetS and its components across quartiles of DPI are presented in Table 3 . In the first model, after adjustment confounders, the risk of MetS $(\mathrm{OR}=0.72,95 \% \mathrm{Cl}=0.55-0.93, \mathrm{P}=0.01)$ and abdominal obesity $(\mathrm{OR}=0.70,95 \% \mathrm{Cl}=0.53-0.93$, $\mathrm{P}=0.01)$ significantly decreased in the second quartiles of DPI compared to the first. Also risk of abdominal obesity in the fourth quartiles of DPI compared to the first significantly decreased $(\mathrm{OR}=0.75,95 \% \mathrm{Cl}=0.58-0.99, \mathrm{P}=0.04)$. In the second model, the risk of MetS $(\mathrm{OR}=0.58,95 \% \mathrm{Cl}=0.38-0.88, \mathrm{P}=0.01)$ and elevated blood pressure $(\mathrm{OR}=0.59$, $95 \% \mathrm{Cl}=0.38-0.92, \mathrm{P}=0.02)$ significantly decreased in the second quartile of DPI compared to the first. In the third model, the risk of MetS (OR=0.63, $95 \%$ $\mathrm{Cl}=0.41-0.96, \mathrm{P}=0.03)$ and elevated blood pressure $(\mathrm{OR}=0.62,95 \% \mathrm{Cl}=0.40-0.96, \mathrm{P}=0.03)$ significantly decreased in the second quartile of $\mathrm{DPI}$ compared to the first.

\section{DPI and MetS and its components stratified by BMI:}

Odds ratio (95\% Cls) of MetS across different categories of DPI stratified by BMI are shown in Table 4. In subjects with normal BMI (BMI $\leq 24.9)$, the risk of MetS significantly decreased in the second quartile of DPI compared to the first $(\mathrm{OR}=0.38,95 \% \mathrm{Cl}=0.16-0.90, \mathrm{P}=0.02)$ after adjustment for possible confounder. In subjects with high BMI (BMI $\geq 24.91)$, higher intake of DPI was related with reduced risk of $\mathrm{MetS}(\mathrm{OR}=0.71,95 \% \mathrm{Cl}=0.52-0.99, \mathrm{P}=0.04)$, after adjustment for age, sex and total energy intake. There was not any significant relationship between DPI and MetS or its components stratified by BMI (data are not shown).

\section{DPI and MetS its components stratified by gender:}

Odds ratio (95\% Cls) of MetS across different categories of DPI stratified by sex are shown in Table 5. In women, after adjustment for confounders, risk of MetS significantly decreased in the highest quartile of $\mathrm{DPI}$ as compared to lowest $(\mathrm{OR}=0.44,95 \% \mathrm{Cl}=0.24-0.80, \mathrm{P}=0.008)$ and $(\mathrm{OR}=0.41,95 \% \mathrm{Cl}=0.22-$ $0.76, P=0.005)$. Men in second category of DPI after adjustment for confounders based on the second model, risk of MetS significantly reduced $(\mathrm{OR}=0.43,95 \% \mathrm{Cl}=0.23-0.83, \mathrm{P}=0.01)$. There was not any significant relationship between $\mathrm{DPI}$ and MetS or its components stratified by sex (data are not shown).

\section{Discussion}

Findings of present study indicated a reduction risk of high blood pressure and MetS with higher adherence to DPI after adjustment the wide range of possible confounder variables. Decrease the risk of abdominal obesity was associated higher DPI follow-up independent of variables including age, sex and total energy intake. Women with most conformity of DPI had lower odds of MetS and participants with normal BMI had lower risk of MetS in a higher DPI. These findings remained significant after full adjustment for confounders. Few studies have examined relationship between DPI with MetS and its risk factors. Therefore, this study aimed to investigate the relationship between DPI with odds of MetS and its components in a large sample of Iranians adults as Middle Eastern countries.

Findings of this study showed a diet with higher DPI were associated with less risk of high blood pressure and MetS. Former publications have manifested a higher amounts of vegetables and fruits [32,33], whole grains [34, 35], nuts [36, 37], legume [38], is inversely associated with a reduction of hypertension. Another studies have shown that consumption of phytochemical abundant foods may prevent hypertension [39, 40]. Data of Korean adults aged $\geq 19$ years discover higher intakes of phytochemical-rich foods are associated with a lower prevalence of MetS. These findings may be ascribed to synergistic effects of phytochemicals, variations their types and their antioxidant and anti-inflammatory properties [39-41]. A longitudinal study on adults stated an increasing energy intake from phytochemicals-rich foods precludes weight gain and adiposity [42]. Another cross-sectional study on 54 adults 18-30 years reported that DPI score was inversely related to WC (25). Protective role of phytochemicals against WC may be mediated by inhibitory role of some polyphenols in proliferation of pre-adipocytes, reduce adipogenesis, and stimulate lipolysis [43, 44]. In this study we found a significant reverse relationship between abdominal obesity and conformity DPI which was consistent with above studies but this relevance did not last long after further adjustments for confounders.

In the present study, one of the beneficial effects of highest compliance of DPI was reduced incidence of MetS in women. A cross sectional study showed a lower risk of the MetS among women with higher intakes of fruit and vegetables [45]. Another study, found moderate and high fruit intake 
could alleviate MetS in women [46]. Some studies have also reported that phytochemicals that found in food sources could improve lipid metabolism in middle-aged women especially with menopause $[47,48]$. Several possible mechanisms that could explain the inverse relationship between MetS and DPI in women include decrease plasma concentrations of C-reactive protein, protection of cellular components against oxidative stress and inflammation, modulate estrogen in women, inhibits blood coagulation and increased intake of antioxidant vitamins such as vitamin A and C [49-52].

A review study presented higher doses of phenolic compounds could have a beneficial effects on the risk factors of MetS (33). Laboratory studies indicated that phytochemicals by their structural diversities, bioavailability, distribution and metabolism can have various effects on human health [53, 54]. In our study, mean score of DPI and also consumption of coffee and tea in women was somewhat higher than men which can probably be attributed to alleviate risk of MetS according to aforesaid explanation.

Current study reveals that participants with normal BMI compare to high BMI had lower risk of MetS in a higher DPI consumption after full adjustment for confounders. Obesity and insulin resistance are among the most important risk factors of MetS [55]. Evidence has shown phytochemical compounds may act through regulate insulin production and secretion and protect pancreatic $\beta$-cells from oxidative stress and induction of GLUT4 membrane activity [56-58].

There is little research on whether different adherence of phytochemical-rich diet has various interactions in subjects stratified by gender and BMI hence, this finding needs to be confirmed with well-conducted studies.

This study had several strengths and limitations. Population-based design was the most important strength of this study. Dietary intakes were assessed with a validated questionnaire. A major limitation of cross-sectional design of this study was that it could not determine the direction of relations. Probability of not considering all possible confounder factors was another. Coffee and tea are rich sources phytochemicals that have not been considered. Dietary phytochemicals quality of participants in the same DPI was not determined in term of variations of intake foods containing phytochemicals. Few studies conducted on the relationship between DPI and MetS with its risk factors.

\section{Conclusions}

More adherence to phytochemical-valuable diet is probably related to reduced risk of MetS especially in women. Follow up of bottom categories of DPI also reduced odds of MetS and some cardio-metabolic risk factors. Therefore, more interventional studies are needed to discover causal relations and relevant underlying mechanisms.

\section{Abbreviations}

DPI: Dietary Phytochemical Index; MetS: metabolic syndrome ; YaHS: Yazd Health Study; TAMYZ: Taghzieh Mardom-e-YaZd; YNS: Yazd Nutrition Survey; FFQ: food frequency questionnaire; WC: Waist circumference; IPAQ : International Physical Activity Questionnaire; MUFA: monounsaturated fatty acids; SFA: saturated fatty acids; PUFA: polyunsaturated fatty acids; HDL-C : Serum high-density lipoprotein cholesterol ; FBS: Fasting blood glucose; DHA: Docosahexaenoic acid; EPA: Eicosapentaenoic acid ; BMI: Body mass index; MET: Metabolic Equivalent; SD: Standard Deviation.

\section{Declarations}

\section{Acknowledgement:}

We thank all the people who participated in this project and committees that supported the research.

\section{Funding :}

This research was funded by Shahid Sadoughi University of Medical Sciences (SSUMS).

\section{Conflict of interest:}

The authors declare that they have no Conflict of interest.

\section{Authors' contribution:}

AA and ZD prepared the proposal, wrote the manuscript and study analysis. MH conceived the idea and supervised the study.MM and AN contributed to the study design. All authors critically reviewed the manuscript and approved the final version submitted for publication.

\section{Availability of data and materials:}

The data set produced or analyzed in this study is not available to the public due to moral and cultural constraints, but is available at the request of the responsible author. 
Written informed consent was obtained from all participants. Ethical approval was obtained from the Ethics Committee of Shahid Sadoughi University of Medical Sciences, No. 17/1/73941.

\section{Consent for publication:}

Not applicable.

\section{References}

1. Lear SA, Gasevic D: Ethnicity and Metabolic Syndrome: Implications for Assessment, Management and Prevention. Nutrients $2019,12$.

2. Kurtoglu S, Akin L, Kendirci M, Hatipoglu N, Elmali F, Mazicioglu M: The absence of insulin resistance in metabolic syndrome definition leads to underdiagnosing of metabolic risk in obese patients. Eur J Pediatr 2012, 171:1331-1337.

3. Practice CRA: Retracted: A Comprehensive Review on Metabolic Syndrome. Cardiol Res Pract 2019, 2019:4301528.

4. Shirani F, Esmaillzadeh A, Keshteli AH, Adibi P, Azadbakht L: Low-carbohydrate-diet score and metabolic syndrome: an epidemiologic study among Iranian women. Nutrition 2015, 31:1124-1130.

5. Povel CM, Boer JM, Onland-Moret NC, Dollé ME, Feskens EJ, van der Schouw YT: Single nucleotide polymorphisms (SNPS) involved in insulin resistance, weight regulation, lipid metabolism and inflammation in relation to metabolic syndrome: an epidemiological study. cardiovasc diabetol 2012, 11:133.

6. Kaur J: Assessment and screening of the risk factors in metabolic syndrome. Med.Sci 2014, 2:140-152.

7. Reaven GM: Diet and syndrome X. Curr. atheroscler. Rep 2000, 2:503-507.

8. Klemsdal TO, Holme I, Nerland H, Pedersen TR, Tonstad S: Effects of a low glycemic load diet versus a low-fat diet in subjects with and without the metabolic syndrome. Nutr METAB Cardiovas 2010, 20:195-201.

9. Feldeisen SE, Tucker KL: Nutritional strategies in the prevention and treatment of metabolic syndrome. APPL PHYSIOL NUTR ME 2007, 32:46-60.

10. Lutsey PL, Steffen LM, Stevens J: Dietary intake and the development of the metabolic syndrome. Circulation 2008, 117:754-761.

11. LaHaye SA, Hollett PM, Vyselaar JR, Shalchi M, Lahey KA, Day AG: Comparison between a low glycemic load diet and a Canada Food Guide diet in cardiac rehabilitation patients in Ontario. CAN J CARDIOL 2005, 21:489-494.

12. Castanho GKF, Marsola FC, Mclellan KCP, Nicola M, Moreto F, Burini RC: Consumption of fruit and vegetables associated with the Metabolic Syndrome and its components in an adult population sample. Cienc 2013, 18:385.

13. Hu FB: Dietary pattern analysis: a new direction in nutritional epidemiology. CURR OPIN LIPIDOL 2002, 13:3-9.

14. van Dam RM: New approaches to the study of dietary patterns. Br. J . NUTR 2005, 93:573-574.

15. Mirzababaei A, Sajjadi SF, Ghodoosi N, Pooyan S, Arghavani H, Yekaninejad MS, Mirzaei K: Relations of major dietary patterns and metabolically unhealthy overweight/obesity phenotypes among Iranian women. Diabetes Metab Syndr: Clinical Research \& Reviews 2019, 13:322-331.

16. Farhangi MA, Najafi M, Jafarabadi MA, Jahangiry L: Mediterranean dietary quality index and dietary phytochemical index among patients candidate for coronary artery bypass grafting (CABG) surgery. BMC CARDIOVASC DISOR 2017, 17:114.

17. McCarty MF: Proposal for a dietary "phytochemical index". Med. hypotheses 2004, 63:813-817.

18. Bahadoran Z, Mirmiran P, Tohidi M, Azizi F: Dietary phytochemical index and the risk of insulin resistance and $\beta$-cell dysfunction: a prospective approach in Tehran lipid and glucose study. Int J FOOD sci nutr 2015, 66:950-955.

19. Bahadoran Z, Golzarand M, Mirmiran P, Saadati N, Azizi F: The association of dietary phytochemical index and cardiometabolic risk factors in adults: Tehran Lipid and Glucose Study. J HUM Nutr DIET 2013, 26:145-153.

20. Mofrad MD, Siassi F, Guilani B, Bellissimo N, Azadbakht L: Association of dietary phytochemical index and mental health in women: A crosssectional study. Br. J. NUTR 2019, 121:1049-1056.

21. Mirzayi BR: Dietary phytochemical index and the risk of breast cancer: a case control study in a population of Iranian women. Asian Pac J Cancer Prev 2013, 14:2747-2751.

22. Vincent HK, Bourguignon CM, Taylor AG: Relationship of the dietary phytochemical index to weight gain, oxidative stress and inflammation in overweight young adults. J HUM Nutr DIET 2010, 23:20-29.

23. Keaney Jr JF, Larson MG, Vasan RS, Wilson PW, Lipinska I, Corey D, Massaro JM, Sutherland P, Vita JA, Benjamin EJ: Obesity and systemic oxidative stress: clinical correlates of oxidative stress in the Framingham Study. Arterioscler Thromb vasc biol 2003, 23:434-439.

24. Hanhineva K, Törrönen R, Bondia-Pons I, Pekkinen J, Kolehmainen M, Mykkänen H, Poutanen K: Impact of dietary polyphenols on carbohydrate metabolism. Int.J. Mol. Sci. 2010, 11:1365-1402.

25. Kahleova H, Matoulek M, Malinska H, Oliyarnik O, Kazdova L, Neskudla T, Skoch A, Hajek M, Hill M, Kahle M: Vegetarian diet improves insulin resistance and oxidative stress markers more than conventional diet in subjects with Type 2 diabetes. Diabet. Med. 2011, 28:549-559.

26. Abshirini M, Mahaki B, Bagheri F, Siassi F, Koohdani F, Sotoudeh G: Higher intake of phytochemical-rich foods is inversely related to prediabetes: $A$ case-control study. Int J Prev Med 2018, 9. 
27. Mirzaei M, Salehi-Abargouei A, Mirzaei M, Mohsenpour MA: Cohort Profile: The Yazd Health Study (YaHS): a population-based study of adults aged 20-70 years (study design and baseline population data). Int. J. Epidemiol 2018, 47:697-698h.

28. Esfahani FH, Asghari G, Mirmiran P, F A: Reproducibility and relative validity of food group intake in a food frequency questionnaire developed for the Tehran Lipid and Glucose Study. Int. J. Epidemiol 2010, 20:150-158.

29. Ghafarpour M, Houshiar-Rad A, Kianfar H, Ghaffarpour M: The manual for household measures, cooking yields factors and edible portion of food. 1999.

30. Kriska AM, Knowler WC, LaPorte RE, Drash AL, Wing RR, Blair SN, Bennett PH, Kuller LH: Development of questionnaire to examine relationship of physical activity and diabetes in Pima Indians. Diabetes Care 1990, 13:401-411.

31. Alberti K: International diabetes federation task force on epidemiology and prevention; hational heart, lung, and blood institute; American heart association; world heart federation; international atherosclerosis society; international association for the study of obesity: harmonizing the metabolic syndrome: a joint interim statement of the international diabetes federation task force on epidemiology and prevention; national heart, lung, and blood institute; American heart association; world heart federation; international atherosclerosis society; and international association for the study of obesity. Circulation 2009, 120:1640-1645.

32. Miura K, Greenland P, Stamler J, Liu K, Daviglus ML, Nakagawa H: Relation of vegetable, fruit, and meat intake to 7-year blood pressure change in middle-aged men: the Chicago Western Electric Study. Am.J.Epidemiol 2004, 159:572-580.

33. Utsugi MT, Ohkubo T, Kikuya M, Kurimoto A, Sato RI, Suzuki K, Metoki H, Hara A, Tsubono Y, Imai Y: Fruit and vegetable consumption and the risk of hypertension determined by self measurement of blood pressure at home: the Ohasama study. HYPERTENS RES 2008, 31:1435-1443.

34. Wang L, Gaziano JM, Liu S, Manson JE, Buring JE, Sesso HD: Whole-and refined-grain intakes and the risk of hypertension in women. Am J CLIN NUTR 2007, 86:472-479.

35. Flint AJ, Hu FB, Glynn RJ, Jensen MK, Franz M, Sampson L, Rimm EB: Whole grains and incident hypertension in men. The American journal of clinical nutrition 2009, 90:493-498.

36. Djoussé L, Rudich T, Gaziano JM: Nut consumption and risk of hypertension in US male physicians. CLin Nutr 2009, 28:10-14.

37. Weng L-C, Steffen LM, Szklo M, Nettleton J, Chambless L, Folsom AR: A diet pattern with more dairy and nuts, but less meat is related to lower risk of developing hypertension in middle-aged adults: the Atherosclerosis Risk in Communities (ARIC) study. Nutrients 2013, 5:1719-1733.

38. Hosseinpour-Niazi S, Mirmiran P, Amiri Z, HOSSEINI EF, Shakeri N, Azizi F: Legume intake is inversely associated with metabolic syndrome in adults. Arch.Iran.Med 2012,15:538-544.

39. Golzarand M, Bahadoran Z, Mirmiran P, Sadeghian-Sharif S, Azizi F: Dietary phytochemical index is inversely associated with the occurrence of hypertension in adults: a 3-year follow-up (the Tehran Lipid and Glucose Study). Eur. J. Clin.Nutr 2015, 69:392-398.

40. Bahadoran Z, Golzarand M, Mirmiran P, Amouzgar A, Azizi F: Association between dietary phytochemical index and occurrence of metabolic syndrome and its risk factors (among Tehranian adults): Tehran Lipid and Glucose Study. Iran J ENDOCRINOL METAB 2012, 14:343-351.

41. Kim M, Park K: Association between phytochemical index and metabolic syndrome. NUTR RES PRACT 2020, 14:252-261.

42. Mirmiran P, Bahadoran Z, Golzarand M, Shiva N, Azizi F: Association between dietary phytochemical index and 3-year changes in weight, waist circumference and body adiposity index in adults: Tehran Lipid and Glucose study. NUTR METAB 2012, 9:108.

43. Tucci SA: Phytochemicals in the control of human appetite and body weight. J.Pharm 2010, 3:748-763.

44. Golzarand M, Mirmiran P, Bahadoran Z, Alamdari S, Azizi F: Dietary phytochemical index and subsequent changes of lipid profile: A 3-year follow-up in Tehran Lipid and Glucose Study in Iran. ARYA atheroscler 2014, 10:203.

45. Esmaillzadeh A, Kimiagar M, Mehrabi Y, Azadbakht L, Hu FB, Willett WC: Fruit and vegetable intakes, C-reactive protein, and the metabolic syndrome. AM J CLIN NUTR 2006, 84:1489-1497.

46. Park S, Ham J-O, Lee B-K: Effects of total vitamin A, vitamin C, and fruit intake on risk for metabolic syndrome in Korean women and men. Nutr.J 2015, 31:111-118.

47. Hong SA, Kim MK: Relationship between fruit and vegetable intake and the risk of metabolic syndrome and its disorders in Korean women according to menopausal status. Asia Pac. J. Clin. Nutr 2017, 26:514.

48. Ko S-H, Kim H-S: Menopause-Associated Lipid Metabolic Disorders and Foods Beneficial for Postmenopausal Women. Nutrients $2020,12: 202$.

49. Hasler CM, Brown AC, American Dietetic A: Position of the American Dietetic Association: Functional foods. J Am Diet Assoc 2009,109:735-746.

50. Srinivasan K: Biological activities of red pepper (Capsicum annuum) and its pungent principle capsaicin: a review. Crit Rev Food Sci Nutr 2016, 56: 1488-1500.

51. Keihanian F, Saeidinia A, Bagheri RK, Johnston TP, Sahebkar A: Curcumin, hemostasis, thrombosis, and coagulation. J. cell.physiol 2018, 233:44974511.

52. Hong J, Kim S-S, Kim HS: Hepatoprotective effects of Soybean Embryo by Enhancing Adiponectin-Mediated AMP-Activated Protein Kinase alpha Pathway in High-Fat and High-Cholesterol Diet-Induced Nonalcoholic Fatty Liver Disease. J Med Food 2016,:549-559.

53. Rice-Evans CA, Miller NJ, Paganga G: Structure-antioxidant activity relationships of flavonoids and phenolic acids. Free Radic Biol Med 1996, 20:933-956. 
54. Middleton E, Kandaswami C, Theoharides TC: The effects of plant flavonoids on mammalian cells: implications for inflammation, heart disease, and cancer. Pharmacol. rev 2000, 52:673-751.

55. Reaven GM: Role of insulin resistance in human disease. Diabetes 1988, 37:1595-1607.

56. Bahadoran Z, Mirmiran P, Azizi F: Dietary polyphenols as potential nutraceuticals in management of diabetes: a review. Journal of diabetes Metab Disord 2013, 12:43.

57. Zhang B, Kang M, Xie $Q, X u B$, Sun $C$, Chen $K$, Wu Y: Anthocyanins from Chinese bayberry extract protect $\beta$ cells from oxidative stress-mediated injury via HO-1 upregulation. J AGR FOOD CHEM 2011, 59:537-545.

58. Park CE, Kim M-J, Lee JH, Min B-I, Bae H, Choe W, Kim S-S, Ha J: Resveratrol stimulates glucose transport in C2C12 myotubes by activating AMPactivated protein kinase. Exp MOL MED 2007, 39:222-229.

\section{Tables}




\begin{tabular}{|c|c|c|c|c|c|c|}
\hline DPI [range] & & $<16.7$ & 16.7-21.6 & 21.7-27.7 & $27.7<$ & \\
\hline $\mathrm{BMI}\left[\mathrm{kg} / \mathrm{m}^{2}\right]$ & $27.11 \pm 4.99$ & $26.88 \pm 4.84$ & $26.87 \pm 4.96$ & $27.25 \pm 5.05$ & $27.43 \pm 5.08$ & 0.14 \\
\hline $\mathrm{WC}[\mathrm{cm}]$ & $93.19 \pm 13.11$ & $93 \pm 13.19$ & $92.5 \pm 13.1$ & $93.1 \pm 13.3$ & $94.1 \pm 12.7$ & 0.2 \\
\hline $20-29$ & 452(19.6) & $128(22.1)$ & 112(19.3) & $99(17.2)$ & 113(19.6) & \\
\hline $30-39$ & $494(21.4)$ & 139(24) & 119(20.5) & 118(20.5) & 118(20.5) & \\
\hline $40-49$ & $567(24.5)$ & $121(20.9)$ & $149(25.7)$ & 169(29.3) & $128(22.2)$ & \\
\hline Male & 1097(47.3) & $270(46.7)$ & $273(47)$ & $281(48.4)$ & $273(47.2)$ & \\
\hline Female & $1220(52.7)$ & $308(53.3)$ & $308(53)$ & $299(51.6)$ & $305(52.8)$ & \\
\hline Marital status; n (\%) & & & & & & 0.62 \\
\hline Married & 2004(86.6) & $510(88.1)$ & $494(85.6)$ & $508(87.6)$ & $492(85)$ & \\
\hline Single & $227(9.8)$ & $48(8.3)$ & 63(10.9) & $54(9.3)$ & $62(10.7)$ & \\
\hline Divorced or widowed & $84(3.6)$ & $21(3.6$ & $20(3.5)$ & 18(3.1) & $25(4.3)$ & \\
\hline Physical activity; n (\%) & & & & & & 0.62 \\
\hline High school diploma & $700(30.4)$ & 182(31.7) & $180(31.2)$ & $164(28.5)$ & 174(30.2) & \\
\hline Smoking; n (\%) & & & & & & 0.75 \\
\hline Never and former & 2074(91.6) & $531(93)$ & $519(91.7)$ & $512(90.1)$ & $512(91.7)$ & \\
\hline Current & $189(8.4)$ & $40(7)$ & $47(8.3)$ & $56(9.9)$ & $46(8.2)$ & \\
\hline Job status; n (\%) & & & & & & 0.86 \\
\hline Not employed & 1373(59.7) & $347(60)$ & $338(59)$ & $339(58.9)$ & $349(61)$ & \\
\hline Employed & $926(40.3)$ & $231(40)$ & $235(41)$ & $237(41.1)$ & 223(39) & \\
\hline \multicolumn{6}{|c|}{ Chronic diseases family history; $\mathbf{n}(\%)$} & 0.49 \\
\hline No & $654(33.6)$ & $141(44.8)$ & 124(39.4) & 124(41.1) & 115(39.7) & \\
\hline Yes & $1292(66.4)$ & $174(55.2)$ & $191(60.6)$ & $178(58.9)$ & $175(60.3)$ & \\
\hline Metabolic syndrome; n (\%) & $1005(45.2)$ & $227(41)$ & $255(45.5)$ & $253(45.3)$ & $270(49.2)$ & 0.05 \\
\hline Abdominal obesity; n (\%) & $1025(44.5)$ & $237(41.1)$ & $257(44.4)$ & $249(43.2)$ & 282(49.2) & 0.04 \\
\hline
\end{tabular}


Abbreviations: $\mathrm{BMI}=$ Body mass index, $\mathrm{WC}=$ waist circumference $\mathrm{DPI}=$ dietary phytochemical index, $\mathrm{Q}=$ quartile, $\mathrm{HDL}-\mathrm{C}=\mathrm{High}-$ density lipoprotein cholesterol, $\mathrm{SD}=$ Standard deviation. FBS= fasting blood sugar.

Data are shown mean \pm SD for $\mathrm{BMI}, \mathrm{WC}$.

Data are shown $\mathrm{n}(\%)$ for all categorical variables. pvalue from ANOVA for continious variables and Chi - square test for categorical.

${ }^{\text {ap }}$ values $<0.05$ were considered significant. 


\begin{tabular}{|c|c|c|c|c|c|c|c|c|c|c|c|}
\hline$p^{a}$ & Q4 & & Q3 & & Q2 & & Q1 & & Total & & \\
\hline & SD & mean & SD & mean & SD & mean & SD & mean & SD & mean & \\
\hline$<0.001$ & 9.2 & 36.08 & 1.79 & 24.53 & 1.36 & 19.4 & 3.15 & 12.5 & 9.95 & 23.13 & Dietary PI \\
\hline$<0.001$ & 1157.02 & 2789.73 & 1110.39 & 2495.22 & 1219.47 & 2650.68 & 1440.08 & 3520.42 & 1298.27 & 2863.76 & $\begin{array}{l}\text { Energy } \\
\text { intake(kca/day ) }\end{array}$ \\
\hline$<0.001$ & 55.18 & 111.65 & 46.91 & 102.37 & 57.99 & 107.93 & 69.13 & 133.26 & 58.98 & 113.8 & Protein(g/day) \\
\hline$<0.001$ & 184.49 & 403.52 & 160.65 & 345.38 & 177.14 & 363.92 & 277.58 & 498.40 & 213.28 & 402.76 & Carbohydrate(g/day) \\
\hline$<0.001$ & 54.41 & 96.24 & 52.12 & 92.27 & 59.99 & 101.80 & 93.97 & 156.78 & 72.15 & 111.76 & Total Fat(g/day) \\
\hline$<0.001$ & 248.73 & 337.64 & 261.88 & 352.21 & 325.27 & 385.51 & 578.68 & 501.18 & 382.97 & 394.11 & Cholesterol(mg/day) \\
\hline$<0.001$ & 13.29 & 26.38 & 13.60 & 26.84 & 16.17 & 29.47 & 23.15 & 41.75 & 18.12 & 31.11 & SFA (g/day) \\
\hline$<0.001$ & 18.16 & 29.13 & 17.59 & 28.07 & 21.08 & 31.65 & 32.36 & 48.61 & 24.52 & 34.36 & MUFA (g/day) \\
\hline$<0.001$ & 24.98 & 28.85 & 15.67 & 23.20 & 20.29 & 25.40 & 31.02 & 36.71 & 24.21 & 28.54 & PUFA (g/day) \\
\hline$<0.001$ & 0.05 & 0.02 & 0.07 & 0.02 & 0.1 & 0.02 & 0.09 & 0.02 & 0.08 & 0.02 & $\mathrm{EPA}(\mathrm{mg} /$ day $)$ \\
\hline$<0.001$ & 0.14 & 0.06 & 0.19 & 0.07 & 0.26 & 0.07 & 0.25 & 0.07 & 0.21 & 0.07 & $\mathrm{DHA}(\mathrm{mg} /$ day $)$ \\
\hline$<0.001$ & 20.31 & 29.71 & 22.51 & 24.48 & 15.83 & 22.83 & 33.24 & 33.70 & 24.21 & 27.68 & Total Fiber(g/day) \\
\hline$<0.001$ & 10.67 & 10.02 & 10.44 & 10.52 & 11.20 & 11.49 & 12.92 & 12.43 & 11.38 & 11.12 & Vitamin E (mg/day) \\
\hline$<0.001$ & 55.62 & 34.57 & 18.52 & 20.07 & 27.55 & 19.77 & 15.64 & 19.11 & 33.91 & 23.38 & Vitamin A (RAE/day) \\
\hline$<0.001$ & 1.04 & 1.18 & 2.33 & 1.48 & 1.73 & 1.46 & 3.67 & 1.85 & 2.40 & 1.49 & Vitamin $\mathrm{D}(\mu \mathrm{g} /$ day $)$ \\
\hline$<0.001$ & 182.90 & 152.70 & 175.61 & 160.26 & 224.99 & 160.03 & 349.82 & 191.19 & 243.82 & 166.04 & Vitamin K( $\mu \mathrm{g} /$ day $)$ \\
\hline$<0.001$ & 269.46 & 279.43 & 142.61 & 202.85 & 135.30 & 182.77 & 111.82 & 164.09 & 181.14 & 207.27 & Vitamin C(mg/day) \\
\hline$<0.001$ & .96 & 2.35 & .84 & 2.06 & .89 & 2.08 & 1.13 & 2.32 & 0.97 & 2.20 & VitaminB1(mg/day) \\
\hline$<0.001$ & .99 & 2.23 & .99 & 2.14 & 1.09 & 2.22 & 1.42 & 2.82 & 1.17 & 2.35 & VitaminB2(mg/day) \\
\hline$<0.001$ & 12.62 & 27.99 & 12.40 & 25.2 & 13.39 & 26.56 & 20.24 & 33.71 & 15.35 & 28.36 & VitaminB3(mg/day) \\
\hline$<0.001$ & 1.27 & 2.47 & 1.26 & 2.2 & 1.38 & 2.32 & 1.80 & 2.95 & 1.47 & 2.50 & VitaminB6(mg/day) \\
\hline$<0.001$ & 257.21 & 431.26 & 169.03 & 341.72 & 200.11 & 336.60 & 194.99 & 377.25 & 211.10 & 371.68 & Folic acid( $\mu \mathrm{g} /$ day $)$ \\
\hline$<0.001$ & 6.02 & 5.1302 & 4.33 & 5.42 & 5.75 & 6.07 & 7.01 & 7.51 & 5.92 & 6.03 & VitaminB12( $\mu \mathrm{g})$ \\
\hline$<0.001$ & 4.40 & 7.28 & 2.73 & 6.04 & 2.69 & 5.87 & 3.12 & 6.61 & 3.35 & 6.45 & $\begin{array}{l}\text { Pantothenic } \\
\text { (mg/day) }\end{array}$ \\
\hline$<0.001$ & 14.73 & 22.73 & 13.02 & 21.07 & 12.63 & 20.88 & 26.04 & 23.70 & 17.52 & 22.09 & Biotin(mg/day) \\
\hline$<0.001$ & 416.80 & 957.90 & 459.49 & 916.33 & 437.01 & 913.69 & 603.06 & 1062.17 & 488.02 & 962.48 & Calcium (mg/day) \\
\hline$<0.001$ & 182.63 & 362.64 & 154.04 & 307.91 & 165.64 & 308.04 & 176.91 & 363.17 & 172.25 & 335.41 & Magnesium(mg/day) \\
\hline$<0.001$ & 2536.55 & 4629.36 & 1869.87 & 3810.11 & 1823.79 & 3652.56 & 1950.44 & 4197.37 & 2098.04 & 4072.06 & Potassium(mg/day) \\
\hline$<0.001$ & 5.67 & 11.98 & 4.71 & 10.77 & 5.63 & 11.17 & 7.05 & 13.66 & 5.93 & 11.90 & Zinc (mg/day) \\
\hline$<0.001$ & 81.72 & 52.29 & 44.42 & 39.77 & 44.58 & 38.99 & 46.98 & 38.28 & 56.92 & 42.33 & $\mathrm{Fe}(\mathrm{mg} /$ day $)$ \\
\hline$<0.001$ & 745.9 & 855.89 & 418.80 & 604.30 & 356.73 & 495.06 & 264.58 & 386.67 & 512.03 & 585.45 & Fruits(g/day ) \\
\hline$<0.001$ & 267.4 & 253.82 & 297.83 & 215.69 & 158.86 & 196.85 & 235.6 & 198.7 & 246.33 & 216.26 & Vegetables (g/day ) \\
\hline$<0.001$ & 83.09 & 58.55 & 36.19 & 44.11 & 38.98 & 40.95 & 59.78 & 45.42 & 58.01 & 47.25 & Legumes (g/day ) \\
\hline$<0.001$ & 49.18 & 31.01 & 22.16 & 18.02 & 20.59 & 17.21 & 34.20 & 25.84 & 34.01 & 23.01 & Nuts (g/day ) \\
\hline$<0.001$ & 92.54 & 99.11 & 59.27 & 77.01 & 51.01 & 68.66 & 53.29 & 49.41 & 68.49 & 73.55 & Whole grains (g/day \\
\hline
\end{tabular}

$\mathrm{DPI}=$ dietary phytochemical index, $\mathrm{Q}=$ quartile.

Data are shown mean \pm SD for all dietary intakes . 


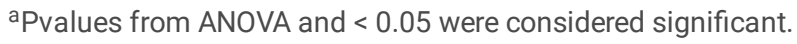

Abbreviations: MUFA= mono-unsaturated fatty acid, PUFA= poly-unsaturated fatty acid, SFA= saturated fatty acid, 


\begin{tabular}{|c|c|c|c|c|c|}
\hline & Q1 & Q2 & Q3 & Q4 & $P$ for trend \\
\hline \multicolumn{6}{|c|}{ Metabolic syndrome } \\
\hline \multirow[t]{2}{*}{ Crude } & 1 (ref.) & $0.71(0.56-0.91)$ & $0.86(0.68-1.09)$ & $0.85(0.67-1.08)$ & 0.01 \\
\hline & & $P=0.006$ & $P=0.20$ & $P=0.20$ & \\
\hline \multirow[t]{2}{*}{ Model $1^{\mathrm{a}}$} & 1 (ref.) & $0.72(0.55-0.93)$ & $0.88(0.68-1.13)$ & $0.88(0.68-1.13)$ & 0.02 \\
\hline & & $P=0.01$ & $P=0.32$ & $P=0.33$ & \\
\hline \multirow[t]{2}{*}{ Model $2^{b}$} & 1 (ref.) & $0.58(0.38-0.88)$ & $0.9(0.6-1.33)$ & $0.79(0.53-1.18)$ & 0.02 \\
\hline & & $P=0.01$ & $P=0.59$ & $P=0.26$ & \\
\hline \multirow[t]{2}{*}{ Model $3^{c}$} & 1 (ref.) & $0.63(0.41-0.96)$ & $0.92(0.61-1.39)$ & $0.78(0.51-1.17)$ & 0.08 \\
\hline & & $P=0.03$ & $P=0.72$ & $P=0.23$ & \\
\hline \multicolumn{6}{|c|}{ Abdominal obesity } \\
\hline \multirow[t]{2}{*}{ Crude } & 1 (ref.) & $0.72(0.57-0.91)$ & $0.82(0.65-1.03)$ & $0.78(0.62-0.98)$ & 0.01 \\
\hline & & $P=0.006$ & $P=0.10$ & $P=0.03$ & \\
\hline \multirow[t]{2}{*}{ Model $1^{a}$} & 1 (ref.) & $0.70(0.53-0.93)$ & $0.81(0.62-1.07)$ & $0.75(0.58-0.99)$ & 0.03 \\
\hline & & $P=0.01$ & $P=0.1$ & $P=0.04$ & \\
\hline \multirow[t]{2}{*}{ Model $2^{b}$} & 1 (ref.) & $0.66(0.42-1.02)$ & $0.82(0.54-1.25)$ & $0.83(0.54-1.26)$ & 0.08 \\
\hline & & $P=0.06$ & $P=0.36$ & $P=0.38$ & \\
\hline \multirow[t]{2}{*}{ Model $3^{c}$} & 1 (ref.) & $0.74(0.43-1.27)$ & $0.86(0.51-1.44)$ & $0.73(0.43-1.23)$ & 0.41 \\
\hline & & $P=0.28$ & $P=0.58$ & $P=0.24$ & \\
\hline \multicolumn{6}{|c|}{ Elevated blood pressure } \\
\hline \multirow[t]{2}{*}{ Crude } & 1 (ref.) & $1.28(0.98-1.69)$ & $1.32(1.01-1.73)$ & $1.41(1.07-1.85)$ & 0.01 \\
\hline & & $P=0.06$ & $P=0.04$ & $P=0.01$ & \\
\hline \multirow[t]{2}{*}{ Model $1^{\mathrm{a}}$} & 1 (ref.) & $1.28(0.95-1.72)$ & $1.32(0.98-1.77)$ & $1.35(1.01-1.81)$ & 0.05 \\
\hline & & $P=0.09$ & $P=0.06$ & $P=0.03$ & \\
\hline \multirow[t]{2}{*}{ Model $2^{b}$} & 1 (ref.) & $0.59(0.38-0.92)$ & $0.81(0.53-1.22)$ & $0.96(0.64-1.45)$ & 0.01 \\
\hline & & $P=0.02$ & $P=0.31$ & $P=0.87$ & \\
\hline \multirow[t]{2}{*}{ Model $3^{c}$} & 1 (ref.) & $0.62(0.40-0.96)$ & $0.83(0.55-1.26)$ & $0.96(0.63-1.45)$ & 0.03 \\
\hline & & $P=0.03$ & $P=0.39$ & $P=0.84$ & \\
\hline \multicolumn{6}{|c|}{ High serum hypertriglyceridemia } \\
\hline \multirow[t]{2}{*}{ Crude } & 1 (ref.) & $0.83(0.65-1.05)$ & $0.86(0.68-1.09)$ & $0.96(0.76-1.22)$ & 0.86 \\
\hline & & $P=0.12$ & $P=0.23$ & $P=0.76$ & \\
\hline \multirow[t]{2}{*}{ Model $1^{a}$} & 1 (ref.) & $0.99(0.77-1.27)$ & $0.83(0.65-1.06)$ & $0.86(0.68-1.1)$ & 0.8 \\
\hline & & $P=0.94$ & $P=0.14$ & $P=0.25$ & \\
\hline \multirow[t]{2}{*}{ Model $2^{b}$} & 1 (ref.) & $1.38(0.94-2.02)$ & $1.2(0.83-1.73)$ & $0.99(0.69-1.44)$ & 0.05 \\
\hline & & $P=0.09$ & $P=0.31$ & $P=0.99$ & \\
\hline \multirow[t]{2}{*}{ Model $3^{c}$} & 1 (ref.) & $1.33(0.9-1.96)$ & $1.16(0.8-1.68)$ & $0.99(0.68-1.45)$ & 0.1 \\
\hline & & $P=0.14$ & $P=0.42$ & $P=0.99$ & \\
\hline \multicolumn{6}{|c|}{ Low serum HDL-C } \\
\hline \multirow[t]{2}{*}{ Crude } & 1 (ref.) & $1.15(0.9-1.47)$ & $1.13(0.88-1.44)$ & $1.13(0.88-1.44)$ & 0.27 \\
\hline & & $P=0.24$ & $P=0.32$ & $P=0.31$ & \\
\hline \multirow[t]{2}{*}{ Model $1^{\mathrm{a}}$} & 1 (ref.) & $1.16(0.9-1.5)$ & $1.12(0.87-1.44)$ & $1.15(0.9-1.48)$ & 0.27 \\
\hline & & $P=0.23$ & $P=0.34$ & $P=0.24$ & \\
\hline
\end{tabular}

Page 13/15 


\begin{tabular}{|c|c|c|c|c|c|}
\hline \multirow[t]{2}{*}{ Model $2^{b}$} & 1 (ref.) & $1.04(0.7-1.55)$ & $1.1(0.75-1.6)$ & $1.06(0.72-1.56)$ & 0.78 \\
\hline & & $P=0.82$ & $P=0.62$ & $P=0.75$ & \\
\hline \multirow[t]{2}{*}{ Model $3^{c}$} & 1 (ref.) & $1.05(0.7-1.55)$ & $1.09(0.75-1.6)$ & $1.06(0.72-1.56)$ & 0.77 \\
\hline & & $P=0.80$ & $P=0.63$ & $P=0.75$ & \\
\hline \multicolumn{6}{|c|}{ High serum FBS } \\
\hline \multirow[t]{2}{*}{ Crude } & 1 (ref.) & $0.96(0.74-1.23)$ & $0.98(0.76-1.25)$ & $1.03(0.81-1.33)$ & 0.65 \\
\hline & & $P=0.75$ & $P=0.88$ & $P=0.76$ & \\
\hline \multirow[t]{2}{*}{ Model $1^{a}$} & 1 (ref.) & $1.02(0.78-1.34)$ & $1.02(0.79-1.33)$ & $1.08(0.83-1.41)$ & 0.94 \\
\hline & & $P=0.84$ & $P=0.84$ & $P=0.53$ & \\
\hline \multirow[t]{2}{*}{ Model $2^{b}$} & 1 (ref.) & $0.91(0.6-1.37)$ & $0.91(0.61-1.35)$ & $1.09(0.73-1.62)$ & 0.48 \\
\hline & & $P=0.66$ & $P=0.65$ & $P=0.66$ & \\
\hline \multirow[t]{2}{*}{ Model $3^{c}$} & 1 (ref.) & $0.94(0.62-1.42)$ & $0.92(0.62-1.38)$ & $1.08(0.72-1.6)$ & 0.59 \\
\hline & & $P=0.77$ & $P=0.71$ & $P=0.70$ & \\
\hline
\end{tabular}

Abbreviations: $\mathrm{OR}=$ odds ratio; $\mathrm{Cls}=$ confidence intervals; $\mathrm{DPI}=$ dietary phytochemical index, Q= quartile. HDL-C= High- density lipoprotein cholesterol, FBS= fasting blood sugar.

Multivariable logistic regression models were used with adjustment of potential confounders.

P for trend to evaluate general trend of odds, DPI of quartiles as ordinal variable was used in logistic regression models

${ }^{a}$ Adjusted for age, sex and energy intake (Kcal/day), b Additional adjustment for marriage status (married/single/divorce or widowed), physical activity (sedentary/moderate/active), education level (less than high school diploma/college/ university), Smoking (never or former, current), job status (Not employed, employed), house status (owner, not owner), family size(less than 4, more than five), house in meters (less than 100 meters, between 100 to 200 meters, more than 200 metres), ethnicity (yazdi or not from yazd), disease history (yes/ no). ${ }^{c}$ Additional adjustment for BMl (kg/m²).

\begin{tabular}{|c|c|c|c|c|c|}
\hline Stratify of BMI & Q1 & Q2 & Q3 & Q4 & $P$ for trend \\
\hline \multicolumn{6}{|l|}{$\mathrm{BMI} \leq 24.9$} \\
\hline \multirow[t]{2}{*}{ Crude } & 1 (ref.) & $0.79(0.49-1.27)$ & $1(0.63-1.59)$ & $0.78(0.48-1.27)$ & 0.56 \\
\hline & & $P=0.33$ & $P=0.98$ & $P=0.33$ & \\
\hline \multirow[t]{2}{*}{ Model $1^{\mathrm{a}}$} & 1 (ref.) & $0.79(0.48-1.29)$ & $0.96(0.6-1.55)$ & $0.79(0.48-1.3 ?)$ & 0.54 \\
\hline & & $P=0.35$ & $P=0.88$ & $P=0.35$ & \\
\hline \multirow[t]{2}{*}{ Model $2^{b}$} & 1 (ref.) & $0.38(0.16-0.90)$ & $0.96(0.44-2.07)$ & $0.98(0.44-2.17)$ & 0.03 \\
\hline & & $P=0.02$ & $P=0.92$ & $P=0.96$ & \\
\hline \multicolumn{6}{|l|}{$\mathrm{BM} \mid>24.9$} \\
\hline \multirow[t]{2}{*}{ Crude } & 1 (ref.) & $0.71(0.53-0.95)$ & $0.85(0.63-1.14)$ & $0.89(0.66-1.2)$ & 0.02 \\
\hline & & $P=0.02$ & $P=0.29$ & $P=0.46$ & \\
\hline \multirow[t]{2}{*}{ Model $1^{a}$} & 1 (ref.) & $0.71(0.52-0.99)$ & $0.87(0.64-1.19)$ & $0.89(0.65-1.22)$ & 0.05 \\
\hline & & $P=0.04$ & $P=0.4$ ? & $P=0.5$ & \\
\hline \multirow[t]{2}{*}{ Model $2^{b}$} & 1 (ref.) & $0.76(0.46-1.25)$ & $0.95(0.59-1.53)$ & $0.75(0.46-1.21)$ & 0.48 \\
\hline & & $P=0.29$ & $P=0.84$ & $P=0.24$ & \\
\hline
\end{tabular}

Abbreviations: $\mathrm{OR}=$ odds ratio; $\mathrm{Cls}=$ confidence intervals; $\mathrm{DPI}=$ dietary phytochemical index, $\mathrm{Q}=$ quartile.

Multivariable logistic regression models were used with adjustment of potential confounders.

P for trend to evaluate general trend of odds, DPI of quartiles as ordinal variable was used in logistic regression models 
${ }^{a}$ Adjusted for age, sex and energy intake (Kcal/day), b Additional adjustment for marriage status (married/single/divorce or widowed), physical activity (sedentary/moderate/active), education level (less than high school diploma/college/ university), Smoking (never or former, current), job status (Not employed, employed), house status (owner, not owner), family size(less than 4, more than five), house in meters (less than 100 meters, between 100 to 200 meters, more than 200 metres), ethnicity (yazdi or not from yazd), disease history (yes/ no).

\begin{tabular}{|c|c|c|c|c|c|}
\hline Stratify of sex & Q1 & Q2 & Q3 & Q4 & $\mathrm{P}$ for trend \\
\hline \multicolumn{6}{|l|}{ Male } \\
\hline \multirow[t]{2}{*}{ Crude } & 1 (ref.) & $0.72(0.49-1.05)$ & $1.04(0.72-1.49)$ & $1.03(0.72-1.48)$ & 0.12 \\
\hline & & $P=0.09$ & $P=0.83$ & $P=0.83$ & \\
\hline \multirow[t]{2}{*}{ Model $1^{a}$} & 1 (ref.) & $0.71(0.48-1.06)$ & $1(0.69-1.44)$ & $1.02(0.71-1.48)$ & 0.12 \\
\hline & & $P=0.09$ & $P=0.99$ & $P=0.88$ & \\
\hline \multirow[t]{2}{*}{ Model $2^{b}$} & 1 (ref.) & $0.43(0.23-0.83)$ & $1.25(0.71-2.19)$ & $1.28(0.72-2.26)$ & 0.02 \\
\hline & & $P=0.01$ & $P=0.42$ & $P=0.39$ & \\
\hline \multirow[t]{2}{*}{ Model $3^{c}$} & 1 (ref.) & $0.54(0.27-1.07)$ & $1.39(0.77-2.51)$ & $1.36(0.74-2.4)$ & 0.15 \\
\hline & & $P=0.08$ & $P=0.27$ & $P=0.31$ & \\
\hline \multicolumn{6}{|l|}{ Female } \\
\hline \multirow[t]{2}{*}{ Crude } & 1 (ref.) & $0.66(0.47-0.92)$ & $0.72(0.51-1)$ & $0.73(0.52-1.02)$ & 0.02 \\
\hline & & $P=0.01$ & $P=0.05$ & $P=0.06$ & \\
\hline \multirow[t]{2}{*}{ Model $1^{a}$} & 1 (ref.) & $0.75(0.52-1.09)$ & $0.82(0.58-1.17)$ & $0.79(0.55-1.13)$ & 0.18 \\
\hline & & $P=0.13$ & $P=0.29$ & $P=0.19$ & \\
\hline \multirow[t]{2}{*}{ Model $2^{\mathrm{b}}$} & 1 (ref.) & $0.76(0.41-1.04)$ & $0.64(0.35-1.17)$ & $0.44(024-0.80)$ & 0.74 \\
\hline & & $P=0.38$ & $P=0.15$ & $P=0.008$ & \\
\hline \multirow[t]{2}{*}{ Model $3^{c}$} & 1 (ref.) & $0.74(0.4-1.38)$ & $0.62(0.34-1.14)$ & $0.41(0.22-0.76)$ & 0.70 \\
\hline & & $P=0.35$ & $P=0.12$ & $P=0.005$ & \\
\hline
\end{tabular}

Abbreviations: $\mathrm{OR}=$ odds ratio; $\mathrm{Cls}=$ confidence intervals; $\mathrm{DPI}=$ dietary phytochemical index, $\mathrm{Q}=$ quartile.

Multivariable logistic regression models were used with adjustment of potential confounders.

P for trend to evaluate general trend of odds, DPI of quartiles as ordinal variable was used in logistic regression models

${ }^{a}$ Adjusted for age, sex and energy intake (Kcal/day). ${ }^{b}$ Additional adjustment for marriage status (married/single/divorce or widowed), physical activity (sedentary/moderate/active), education level (less than high school diploma/college/ university), Smoking (never or former, current), job status (Not employed, employed), house status (owner, not owner), family size(less than 4, more than five), house in meters (less than 100 meters, between 100 to 200 meters, more than 200 metres), ethnicity (yazdi or not from yazd), disease history (yes/ no). ${ }^{\mathrm{c}}$ Additional adjustment for BMl (kg/m²). 